\title{
A Case Report on Ancylostoma Duodenale Infection in Pregnant Woman
}

\author{
Priti Karadbhajne ${ }^{1}$, Anil Tambekar ${ }^{2}$, Abhay Gaidhane ${ }^{3}$, \\ Zahiruddin Quazi Syed ${ }^{3}$ and Shilpa Gaidhane ${ }^{4}$ \\ ${ }^{1}$ Research \&t Development, Datta Meghe Institute \\ of Medical Sciences, Sawangi (M), Wardha. \\ ${ }^{2}$ Junior Research fellow, Research \&t Development, Datta Meghe \\ Institute of Medical Sciences, Sawangi (M), Wardha. \\ ${ }^{3}$ School of Epidemiology and Public Health Datta Meghe \\ Institute of Medical Sciences, Sawangi (M), Wardha \\ ${ }^{4}$ Associate professor, JNMC, Datta Meghe Institute of Medical \\ Sciences, Sawangi (M), Wardha. \\ Corresponding author email: zahirquazi@gmail.com
}

\begin{abstract}
The hookworm infection is the leading neglected tropical disease among the 20 diseases listed by WHO. Ancylostoma duodenale and Necator americanus are two principal species of hookworm known to infect humans. A. duodenale is a soil transmitted helminths. Hookworm infection gives rise to iron deficiency anemia (IDA), stable weight, tiredness, etc. in a pregnant woman. The main infection route for Ancylostoma duodenale is in humans is through the skin. Each worm sucks the blood between 0.1 to $0.4 \mathrm{ml}$ of blood /day. The blood loss due to hookworm can be $250 \mathrm{ml} /$ day in heavy infection. Iron Deficiency Anaemia is common in hookworm infected patients. This case was encountered during a survey on awareness of healthy habits during pregnancy in the study area. The woman was enrolled in our field survey. The woman was found to be positive for infection of Ancylostoma duodenale in her 2nd trimester as reported by RT-PCR and Microbiological study of feacal samples. Hookworm infection is still an important issue for community health even after the health education programs and early intervention can help to tackle future complications.
\end{abstract}

KEY WORDS: PREGNANCY, HOOKWORM INFECTION, ANCYLOSTOMADUODENALE, ANEMIA, RT-PCR, MICROSCOPY.

\section{INTRODUCTION}

The origin of the human hookworm infection commonly causes due to poor socioeconomic status, poor sanitation, sewage disposal, unhygienic health habit and unhealthy, uncooked food, etc. It can spread through pet animals like pet dog, cat etc.because dogs and cats which are

Biosc Biotech Res Comm P-ISSN: 0974-6455 E-ISSN: 2321-4007

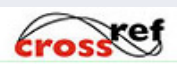

Identifiers and Pagination

Year: 2021 Vol: 14 No (6) Special Issue

Pages: $100-103$

This is an open access article under Creative

Commons License Attribn 4.0 Intl (CC-BY).

DOI: $h$ ttp://dx.doi.org/10.21786/bbrc/14.6.23 the definitive host of Ancylostoma species. Deworming of these animals become very essential to avoid A. duodenale infection. Hookworm infection gives rise to iron deficiency anemia (IDA), stable weight, tiredness, etc. in a pregnant woman. IDA produces many healthrelated problems in children and pregnant women. IDA is responsible for the stunted growth of the fetus, it also affects mental health in women and children (Mohapatra et al., 2015). All of the body systems can be mainly affected by helminths, but mostly influence the gastrointestinal system (Tan et al., 2017; Syed et al., 2016).

The most common route of transmission of hookworm is through fecal-oral-route. Transmission of hookworm infection in children occurs if children lie barefoot on the 
soil (Karadbhajane et al., 2020; Tambekar et al., 2020). Another route of transmission will be breastfeeding milk from infected mothers to infants. The main infection route for Ancylostoma duodenale is through the skin (Simarmata et al., 2015; Karadbhajne et al., 2020).

Each worm sucks the blood between 0.1 to $0.4 \mathrm{ml}$ of blood/day. The blood loss due to hookworm can be $250 \mathrm{ml} /$ day in heavy infection. Iron Deficiency Anaemia is common in hookworm infected patients. IDA occurs due to intestinal blood loss caused by hookworm. The erosion due to the biochemical action of the secretion of a hydrolytic enzyme, anticoagulants, and teeth characteristic of each species caused hemorrhages that follow blood loss in anemia (Giraldo-Forero et al., 2020; Baltz et al., 2009). In the case report, poor socioeconomic status, fieldwork, poor hygienic habit implies the worst effect for a pregnant woman. This case proves that blood and iron deficiency in a pregnant woman is caused by Ancylostoma duodenale due to the blood-sucking feature of hookworm. IDA prevalence is common in pregnant women.

Presentation of case: Our field survey, team of DMIMS, Sawangi, Wardha was working on a project related to pregnant woman health. The team was equipped with a material kit essential for stool and blood samples. The field surveyor advised the women about water purification, the importance of good personal hygiene procedures, not to walk barefoot, etc. The precautions in pregnancy to avoid any disease were given by our team to the pregnant woman.

Patient Information: 23-year-old pregnant woman in her 2nd trimester from the village of Wardha district was enrolled for a field survey of DMIMS, Sawangi, Wardha. The woman complains of passing black colored stool, vomiting, feeling fainting sensation for 8 days during the examination. After examining up to 22 weeks, steady weight was noted, but all pulse, heartbeat, etc were normal. There was no complaint of fever, white discharge, and others. No significant surgical history was present. Pregnant woman enrolled in our field survey, verbal informed consent was taken from a pregnant woman. The patient gave history about last week's abdominal pain. The patient history was taken by us with information on age, height, weight, and others.

\section{Differential Diagnosis:}

Microscopy: Fresh morning stool sample was collected from the pregnant woman. The collected stool samples were immediately transferred in the plastic carrier box containing ice packs to avoid any damage to the samples and then deliberately transported to the research laboratory. The collected sample was divided as per the requirement of the laboratory procedure. The stool sample was distributed into two parts-One part was used for microscopic analysis immediately and the other part was stored for PCR assay at $-20^{\circ} \mathrm{C}$. No adult worms were present in the stool, but eggs of the worm were present. The microscopic examination of the stool was positive for the parasite.
Clinical diagnosis: The blood sample was taken and a complete blood count was investigated. The hemoglobin was $6 \mathrm{~g} / \mathrm{dl}$. This reading proves the anemic nature of the woman. A woman was advised to admit to the hospital for further treatment.

Figure 1: Microscopic images showing Ancylostoma duodenale

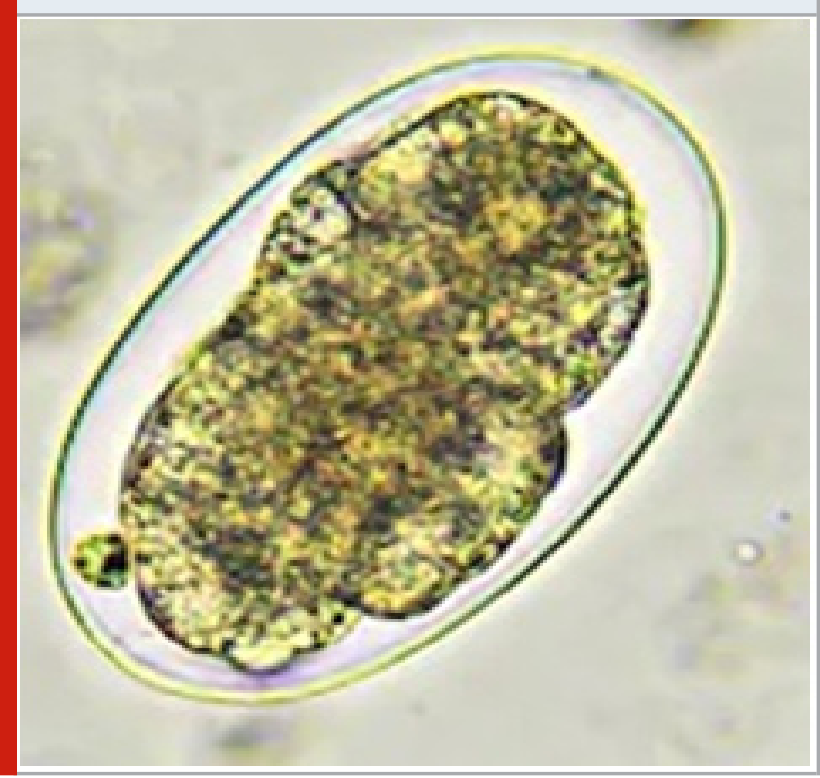

Figure 2: q PCR graph showing positive result for Ancylostoma duodenale

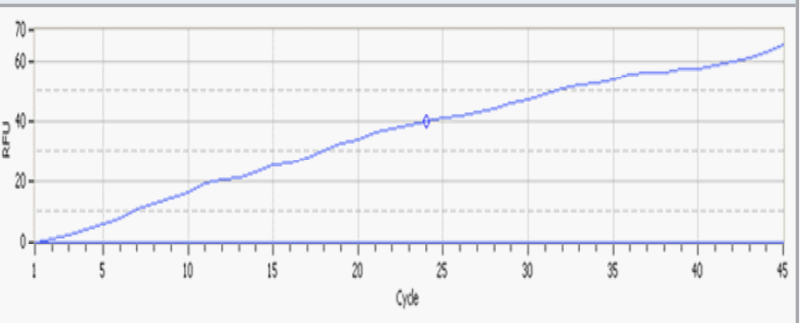

DNA Extraction and Molecular technique: DNA extraction from a stored stool sample was done by using the Hi-media kit. In the RT-PCR, the 20 ul reaction mixture consists of $1 \mathrm{x}$ Tag-man mixture, forward primer, reverse primer, probe, nuclease-free water, DNA. If the CT value is $\leq 42$ and had an exponential curve then the sample will be considered as a positive. The molecular technique result was positive for Ancylostoma duodenale. The advice was given to the patient to admit to the hospital. The patient had been under follow up for 2 months with no symptoms of Ancylostoma duodenale.

Discussion of management: The economic situation of rural women and working as labor women in India is dire. Therefore, even during pregnancy, they have to carry out all the chores in the field or at home. Since most of the women in the village have dropped out of school, they have little or no knowledge of health issues, so during pregnancy, they follow the rules that are passed on to them by their parents. They don't need to see how right 
and wrong these rules are (Zodpey et al., 2018; Patel et al., 2018). Malnutrition, improper disposal of sewage, and non-availability of potable water supplies especially become responsible for the infection of Ancylostoma duodenale in India. Poor sanitation, scarcity of potable drinking water, and the low standard of personal hygiene contribute the share in the rapid spread of the infection (Bhatawadekar et al., 2015; Pierce et al., 2019). Ancylostomaduodenale contributes to malnutrition, growth retardation, and diminished work capacity.

Hookworm eggs hatch in the soil, releasing larvae that mature into a form that can actively penetrate the skin. People become infected with Ancylostoma duodenale primarily by walking barefoot on the fecal contaminated soil. Direct person to person transmission and infection from fresh feces is not possible, because eggs passed in feces require 3 weeks to mature in the soil before they become infective (Thowet al., 2017; Tambekar et al., 2020;Regmi et al., 2020). Since her place of residence was a village, she had to do all kinds of household chores which were considered normal and routine in the village. She cleans the house with dung every day. She cleans the cow shed daily and does all the work barefoot. She was owner of cat and dog too. So it was natural for her to get infected with hookworms.

\section{CONCLUSION}

Routine housework in the village can be a sufficient reason for getting an infection of hookworms like Ancylostomaduodenale. Following appropriate WaSH Practices is mandatory to prevent such infections and related complications. A thorough awareness and WaSH campaign needs to be implemented for pregnant women in rural areas.

\section{Conflict of Interest: Nil}

Funding: Public Health Foundation of India (PHFI).

\section{REFERENCES}

Baltz, J.G., Mishra, R. and Yeaton, P., 2009. Unusual case of hookworm presenting as acute surgical abdomen. American Journal of Medicine, 122(2).

Bhatawadekar D. Hookworm Infestation in Infant : A Rare Case Report. :1 ., 2015

Gaidhane, A.M. and Zahiruddin, Q.S., Protocol on Causal Chain Analysis and Health Economic Modelling of Childhood Anaemia Interventions in Developing Countries-A Health Technology Assessment.

Giraldo-Forero, J.C., Muñoz-Niño, L.A. and CoronadoCastiblanco, K.V., 2019. Severe iron anemia deficiency caused by hookworm: Case report and literature review. Rev Med Hosp Gen Mex, 82(4), pp.215-220..

Karadbhajane P.., Tambekar A., Gaidhane A., Zahiruddin Z. Q., Gaidhane S., Patil M., Giardiasis in tropical region in the state of Maharashtra: case series. July-2020, https://doi.org/10.13140/RG.2.2.12686.18248
Karadbhajne, P., Tambekar, A., Gaidhane, A., Syed, Z.Q., Gaidhane, S. and Patil, M., 2020. Amoebiasis in pregnant woman: A case report. Medical Science, 24(104), pp.1814-1817.

Latchoumi, T.P., Ezhilarasi, T.P. and Balamurugan, K., 2019. Bio-inspired weighed quantum particle swarm optimization and smooth support vector machine ensembles for identification of abnormalities in medical data. SN Applied Sciences, 1(10), pp.1-10.

Patel, A., Khatib, M.N., Kurhe, K., Bhargava, S. and Bang, A., 2017. Impact of neonatal resuscitation trainings on neonatal and perinatal mortality: a systematic review and meta-analysis. BMJ paediatrics open, 1(1).

Pierce, D., Merone, L., Lewis, C., Rahman, T., Croese, J., Loukas, A., McDonald, M., Giacomin, P. and McDermott, R., 2019. Safety and tolerability of experimental hookworm infection in humans with metabolic disease: study protocol for a phase $1 \mathrm{~b}$ randomised controlled clinical trial. BMC endocrine disorders, 19(1), pp.1-11. Regmi, P.R., Van Teijlingen, E., Mahato, P., Aryal, N., Jadhav, N., Simkhada, P., Syed Zahiruddin, Q. and Gaidhane, A., 2019. The health of Nepali migrants in India: A qualitative study of lifestyles and risks. International journal of environmental research and public health, 16(19), p.3655.

Ronquillo, A.C., Puelles, L.B., Espinoza, L.P., Sánchez, V.A. and Luis Pinto Valdivia, J., 2019. Ancylostoma duodenale as a cause of upper gastrointestinal bleeding: a case report. Brazilian Journal of Infectious Diseases, 23(6), pp.471-473.

Sharma, B., Mohapatra, S., Kumar, A. and Deb, M., 2015. Diagnostic dilemma in hookworm infection: An unusual case report. Indian journal of medical microbiology, 33(1), p.179.

Sharma, B., Mohapatra, S., Kumar, A. and Deb, M., 2015. Diagnostic dilemma in hookworm infection: An unusual case report. Indian journal of medical microbiology, 33(1), p.179.

Simarmata, N., Sembiring, T. and Ali, M., 2015. Nutritional status of soil-transmitted helminthiasis-infected and uninfected children. Paediatrica Indonesiana, 55(3), pp.136-41.

Tambekar, A., Burnase, N., Gaidhane, A., Fulzele, P. and Syed, Z.Q., 2020. Foldscope assisted microscopy for the examination of Soil Transmitted Helminths (STH). Medical Science, 24(101), pp.102-106.

Tambekar, A., Burnase, N., Gaidhane, A., Fulzele, P. and Syed, Z.Q., 2020. Comparison of two microscopic methods for the detection of parasitic infection in antenatal women in selected areas. Medical Science, 24(102), pp.557-564.

Tan, X., Cheng, M., Zhang, J., Chen, G., Liu, D., Liu, Y. and Liu, H., 2017. Hookworm infection caused 
acute intestinal bleeding diagnosed by capsule: a case report and literature review. The Korean journal of parasitology, 55(4), p.417.

Thow, A.M., Karn, S., Devkota, M.D., Rasheed, S., Roy, S.K., Suleman, Y., Hazir, T., Patel, A., Gaidhane, A., Puri, S. and Godakandage, S., 2017. Opportunities for strengthening infant and young child feeding policies in South Asia: Insights from the SAIFRN policy analysis project. BMC Public Health, 17(2), pp.5-14.
Zahiruddin, Q.S., Kogade, P., Kawalkar, U., Khatib, N. and Gaidhane, S., 2016. Challenges and Patterns of Complementary Feeding for Women In Employment: A Qualita-tive Study from Rural India. Current Research in Nutrition and Food Science Journal, 4(1), pp.48-53.

Zodpey, S., Sharma, A., Zahiruddin, Q.S., Gaidhane, A. and Shrikhande, S., 2018. Allopathic doctors in India: estimates, norms and projections. Journal of Health Management, 20(2), pp.151-163. 